\title{
ANALISIS STRATEGI PENGEMBANGAN OBYEK WISATA PABANGBON DI KABUPATEN BOGOR
}

\author{
Riani Prihatini Ishak ${ }^{1}$ \\ rianipishak@gmail.com \\ Sekolah Tinggi Pariwisata Bogor \\ Prabowo Eko Julianto ${ }^{2}$ \\ Prabowoekojulianto18@gmail.com \\ Sekolah Tinggi Pariwisata Bogor
}

\begin{abstract}
The development of a tourist attraction in one area will determine the level of its income. Tourist satisfaction is an important factor in the development of tourist objects. Panorama Pabangbon is a natural tourist attraction at an altitude of 720 meters, and is one of the newest tourist objects in Bogor, since its appearance on social media in early 2017 , it has immediately attracted people attention because apart from offering a natural atmosphere typical of pine forests, this recreation area has also been equipped with various interesting facilities. Development strategy for the Pabangbon Panorama Tourism Area tourist attraction is the key to the sustainability of this tourism object and to attract more tourists who visit, this is the background of conduction of this research. The method used is descriptive qualitative research with strategy design using SWOT analysis. In this study, it was found that promotional activities that are still lacking, facilities and infrastructure that are still inadequate are weaknesses that must be properly considered by management, by taking into account the high opportunities, including high desire to travel and high support from residents and tourists as well as open cooperation with the government, according to the results of the analysis, it can be concluded that the turnaround strategy is most appropriate for the development of the Panorama Pabangbon tourist attraction.
\end{abstract}

Key words: Pabangbon Panorama Tour, SWOT Analyses, Nature Tourism Development Strategy

\begin{abstract}
ABSTRAK
Pengembangan objek wisata suatu daerah akan menentukan tingkat pendapatan di suatu daerah. Kepuasan wisatawan menjadi faktor penting dalam upaya pengembangan objek wisata. Panorama Pabangbon adalah objek wisata alam di ketinggian 720 meter, dan merupakan salah satu obyek wisata terbaru di Bogor, sejak kemunculannya di media sosial pada awal 2017 langsung menarik perhatian karena selain menawarkan suasana alami khas hutan pinus, tempat rekreasi ini juga telah dilengkapi dengan berbagai wahana yang menarik. Strategi pengembangan objek wisata Pabangbon Panorama Tourism Area yang berkelanjutan merupakan kunci keberlangsungan objek wisata ini dan agar lebih banyak menarik wisatawan yang berkunjung, sehingga penelitian ini dilakukan. Metode yang digunakan
\end{abstract}


penelitian deskriptif kualitatif dengan perancangan strategi menggunakan analisis SWOT. Dalam penelitian ini ditemukan bahwa Kegiatan promosi yang masih kurang, sarana dan prasarana yang masih kurang memadai merupakan kelemahan yang harus diperhatikan benar oleh pengelola, dengan memperhatikan peluang yang tinggi antara lain tingginya keinginan untuk berwisata dan adanya dukungan yang tinggi dari penduduk maupun wisatawan serta terbukanya kerjasama dengan pemerintah maka sesuai hasil analisis dapat disimpulkan bahwa strategi turnaround yang paling tepat digunakan untuk pengembangan objek wisata Panorama Pabangbon.

Kata Kunci: Wisata Panorama Pabangbon, Analisis SWOT, strategi pengembangan objek wisata alam.

\section{PENDAHULUAN}

Berwisata merupakan kebutuhan setiap individu karena aktivitas bepergian untuk seorang individu dapat meningkatkan daya kreatif, menghilangkan kejenuhan pekerjaan, relaksasi, belanja, bisnis, mengetahui warisan sejarah dan budaya dari etnis tertentu, kesehatan dan spiritualisme pariwisata. Dengan bertambahnya waktu luang sebagai akibat dari hari kerja yang lebih pendek dan didukung oleh peningkatan pendapatan, kegiatan pariwisata akan meningkat (Yuwana, 2010: 1). Pariwisata adalah salah satu industri gaya baru, yang mampu memberikan pertumbuhan ekonomi yang cepat dalam hal peluang kerja, pendapatan, standar hidup dan dalam mengaktifkan sektor produksi lain di dalam negara penerima (Wahab, 2012: 5). Karena itu pengembangan pariwisata di suatu daerah akan membawa banyak manfaat bagi perekonomian, sosial dan budaya bagi masyarakat, apabila perkembangannya dipersiapkan dan dikelola dengan baik.

Bogor telah menjadi tujuan wisata populer, selain cukup dekat dari kotakota besar seperti Jakarta, Bandung, Sukabumi dan lain-lain, kota Hujan ini terkenal karena memiliki deretan tempat wisata menarik karena Bogor memiliki topografi lanskap dataran tinggi yang khas. Salah satunya adalah Desa Wisata Pabangbon yang dikelola oleh Pemerintah Desa adalah di Desa Pabangbon, Kecamatan Leuwiliang, Kabupaten Bogor Utara. Desa ini memiliki tempat perkemahan dan spot-spot foto dengan pemandangan sangat indah. Pesona Wisata Panorama Pabangbon yang terkenal dengan Pabangbon Leuwiliang Hill adalah objek wisata baru muncul di medsos awal tahun 2017 namun cukup berhasil langsung menarik perhatian, karena wisata ini memadukan suasana alam hutan pinus dengan berbagai wahana yang menyenangkan. Panorama Pabangbon adalah objek wisata alam di ketinggian 720 meter di atas permukaan laut dengan konsep rumah pohon yang memiliki banyak spot berfoto yang instagramable. Dengan potensi yang ada desa wisata ini, maka pengembangkan objek wisata Pabangbon Panorama Tourism Area adalah langkah strategik yang perlu diambil, agar lebih banyak wisatawan yang berkunjung.

Unsur yang dapat mendukung sebuah objek wisata bisa berkembang ada 4 (empat) yaitu atraksi, akomodasi, aksesibilitas dan amenitas atau yang biasa disebut konsep 4A. Penelitian dilakukan untuk menciptakan strategi pengembangan objek wisata yang sesuai untuk Pantai Palangpang. Strategi pengembangan wisata 
diharapkan dapat meningkatkan partisipasi berbagai pihak (Batubara, 2019). Atraksi dapat pula berupa kegiatan yang dapat dilakukan. Tanpa adanya kegiatan, maka tidak akan ada wisatawan yang datang berkunjung (Sari, 2017). Strategi pengembangan diharapkan dapat digunakan oleh pihak berkepentingan untuk membuat Pantai Palapang lebih diminati wisatawan, sehingga dapat memberikan kontribusi bagi masyarakat setempat, karena tanpa hadirnya wisatawan tidak akan ada kontibusi dalam pertumbuhan ekonomi (Sari, 2018), dan untuk wisatawan akan datang bila ada dorongan bila ada yang melatarbelakanginya (Sari, 2019).

Berdasarkan penjelasan Latar Belakang, menjadi menarik untuk dilakukan penelitian "Analisis Strategi Pengembangan Objek Wisata Pabangbon di Kabupaten Bogor" dengan rumusan masalah bagaimana strategi pengembangan yang tepat untuk diterapkan dalam meningkatkan jumlah pengunjung objek Wisata Pabangbon di Kabupaten Bogor. Penelitian ini bertujuan untuk merumuskan strategi pengembangan yang tepat yang harus dilakukan oleh pengelola objek Wisata Pabangbon untuk meningkatkan jumlah pengunjung objek Wisata Pabangbon di Kabupaten Bogor.

Sesuai dengan tujuan dan sasaran penelitian penulis berharap penelitian ini dapat memberikan manfaat dan kegunaan antara lain : (1) sebagai sumber informasi bagi pembuat kebijakan dan pertimbangan yang tepat untuk meningkatkan kepariwisataan, khususnya di Kabupaten Bogor, (2) sebagai masukan bagi pengelola Panorama Obyek Wisata Pabangbon dalan perumusan strategi pengembangannya, (3) memperkaya hasil penelitian terkait dengan strategi pengembangan pariwisata serta strategi alternatif lainnya, (4) kiranya hasil penelitian ini dapat menambah pengetahuan, informasi dan referensi yang berguna bagi penelitian- penelitian selanjutnya.

\section{METODOLOGI}

Metode yang digunakan dalam penelitian ini adalah metode deskriptif kualitatif, yaitu penelitian ilmiah yang sistematis pada bagian-bagian dan fenomena dan hubungan mereka. Penelitian bersifat penelitian deskriptif dengan pendekatan survey eksploratif yaitu dengan meninjau langsung obyek penelitian hingga faktorfaktor yang dibutuhkan dalam pembuatan strategi. Sumber data terdiri dari masyarakat sebanyak 30 responden, wisatawan sebanyak 30 responden, pengelola dan pemerintah. Teknik pengumpulan data dilakukan dengan wawancara, penelaahan pustaka dan kuesioner. Data yang didapatkan dianalisis dengan mempertimbangkan kekuatan, kelemahan, peluang dan ancaman.

Tabel 1.

Sumber Data

\begin{tabular}{|l|l|l|}
\hline No. & Jenis Data & \multicolumn{1}{|c|}{ Sumber Data } \\
\hline 1. & Data Primer & $\begin{array}{l}\text { Data diperoleh dari hasil penelitian dari } \\
\text { observasi di Pabangbon Tourism }\end{array}$ \\
\hline 2. & Data Sekunder & - Manajemen Pariwisata Pabangbon \\
\hline
\end{tabular}




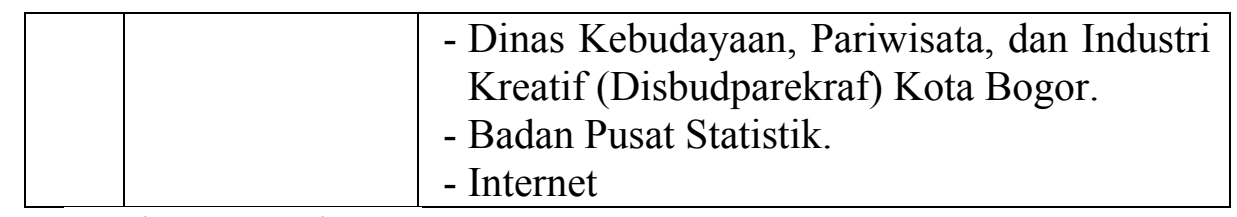

Sumber : Jurnal 2018

Tabel 2.

Variabel Penelitian

\begin{tabular}{|c|c|c|c|}
\hline Variabel & Definisi Operasional & Measurement & $\begin{array}{l}\text { Target } \\
\text { Respondent }\end{array}$ \\
\hline $\begin{array}{l}\text { Faktor } \\
\text { Eksternal }\end{array}$ & $\begin{array}{l}\text { Kekuatan Eksternal: } \\
\text { 1. Kekuatan Ekonomi } \\
\text { 2. Kekuatan Sosial, Budaya } \\
\text { dan Lingkungan } \\
\text { 3. Kekuatan Politik dan } \\
\text { Hukum } \\
\text { 4. Kekuatan Teknologi } \\
\text { PELUANG: } \\
\text { Sektor pariwisata berkembang } \\
\text { dan teknologi berkembang. } \\
\text { ANCAMAN: } \\
\text { Persaingan Pariwisata, } \\
\text { bencana, kurangnya } \\
\text { transportasi umum, kurangnya } \\
\text { dukungan dari pemerintah } \\
\text { daerah }\end{array}$ & 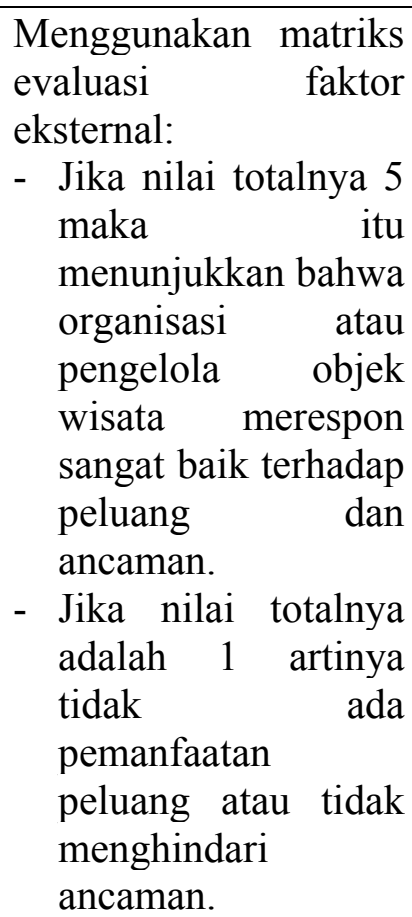 & $\begin{array}{l}\text { Responden } \\
\text { adalah } \\
\text { pengunjung } \\
\text { Objek Wisata } \\
\text { Panorama } \\
\text { Pabangbon yang } \\
\text { sedang } \\
\text { berkunjung ke } \\
\text { objek wisata ini. }\end{array}$ \\
\hline $\begin{array}{l}\text { Faktor } \\
\text { Internal }\end{array}$ & $\begin{array}{l}\text { Berdasarkan } \\
\text { berbasis sumber daya yang } \\
\text { dipelopori oleh Jay Barney, } \\
\text { pengunjung ke objek wisata } \\
\text { menyatakan bahwa sumber } \\
\text { daya pariwisata internal } \\
\text { Pabangbon dapat } \\
\text { dikelompokkan ke dalam tiga } \\
\text { kategori: } \\
\text { 1. Sumber daya fisik yang } \\
\text { mencakup semua atraksi, } \\
\text { peralatan, lokasi, teknologi } \\
\text { ini. } \\
\text { 2. Sumber daya manusia yang } \\
\text { meliputi karyawan, } \\
\text { pengalaman } \\
\text { kemampuan. }\end{array}$ & $\begin{array}{l}\text { Menggunakan matriks } \\
\text { evaluasi faktor internal: } \\
\text { - Jika total skor rata- } \\
\text { rata di bawah } 2,5 \\
\text { artinya organisasi } \\
\text { lemah secara internal. } \\
\text { - Jika total nilai di atas } \\
\text { 2,5 artinya organisasi } \\
\text { memiliki posisi } \\
\text { internal yang kuat. }\end{array}$ & $\begin{array}{l}\text { Responden } \\
\text { adalah } \\
\text { pengunjung } \\
\text { Atraksi } \\
\text { Panorama } \\
\text { Pabangbon yang } \\
\text { mengunjungi } \\
\text { objek wisata ini. }\end{array}$ \\
\hline
\end{tabular}




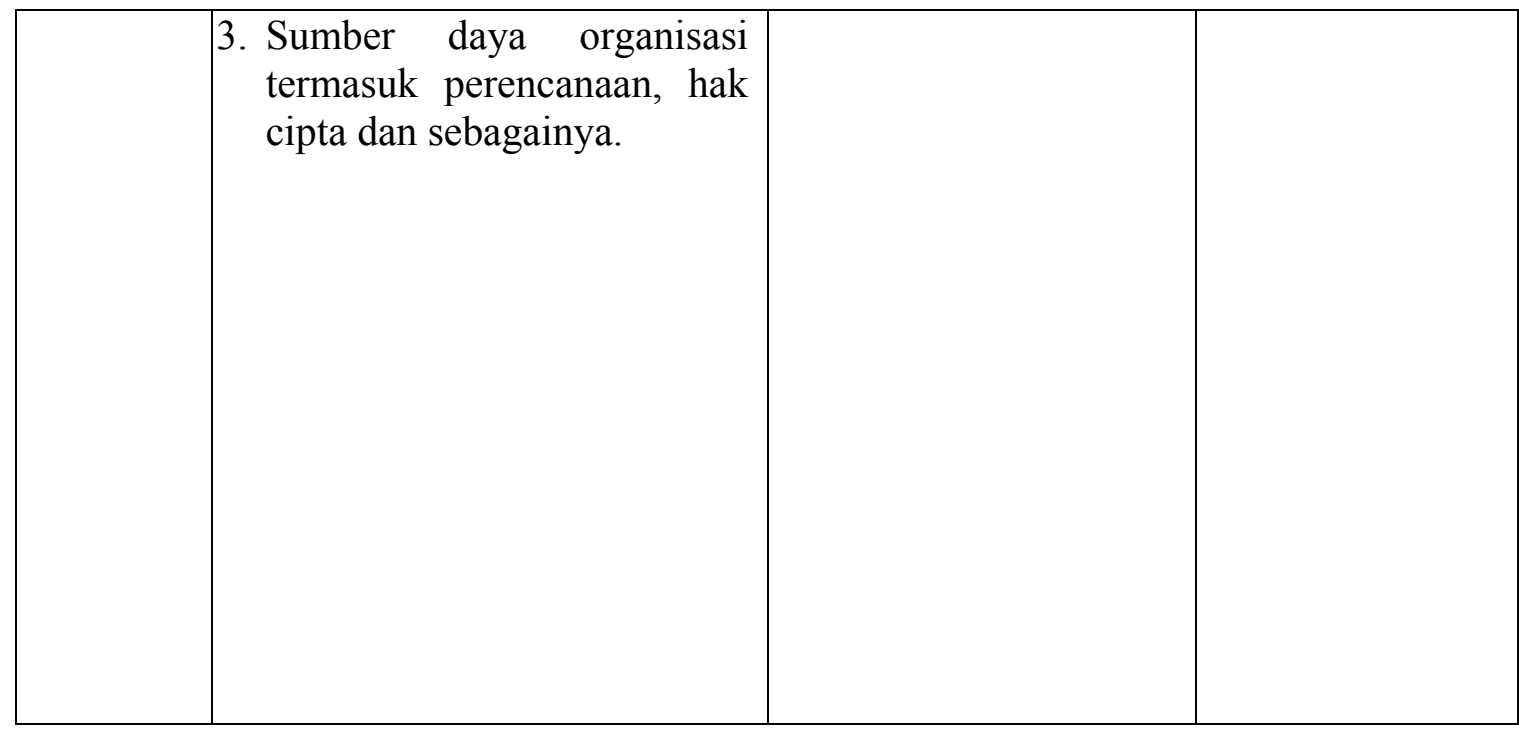

\section{HASIL DAN PEMBAHASAN}

Pariwisata yang terkenal di Bogor adalah Wisata Budaya, Wisata Alam, dan Wisata Kuliner. Dinas Kebudayaan dan Pariwisata Kabupaten Bogor menetapkan strategi dan target berikut untuk kepariwisataannya yaitu meningkatkan sumber daya pariwisata yang berwawasan luas dan berkelanjutan dengan fokus pada kegiatan peningkatkan kualitas pelayan pariwisata, mewujudkan bimbingan dan pengawasan daya tarik objek wisata berkelanjutan, mewujudkan rencana pengembangan pariwisata dan mengoptimalkan kinerja Sumber Daya Manusia di bidang pariwisata dengan tujuan meningkatkan kesadaran dan partisipasi masyarakat dalam konservasi lingkungan pariwisata dengan cara meningkatkan pemanfaatan sumber daya pariwisata, meningkatkan manajemen dan pengembangan pariwisata berbasis domestik sesuai dengan prinsip pengembangan pariwisata yang terintegrasi dan berkelanjutan, meningkatkan sarana dan prasarana pariwisata, dan ketersediaan kawasan wisata untuk kebutuhan masyarakat. Salah satu objek wisata alam yang berpotensi besar untuk dikembangkan adalah objek wisata Panorama Pabangbon

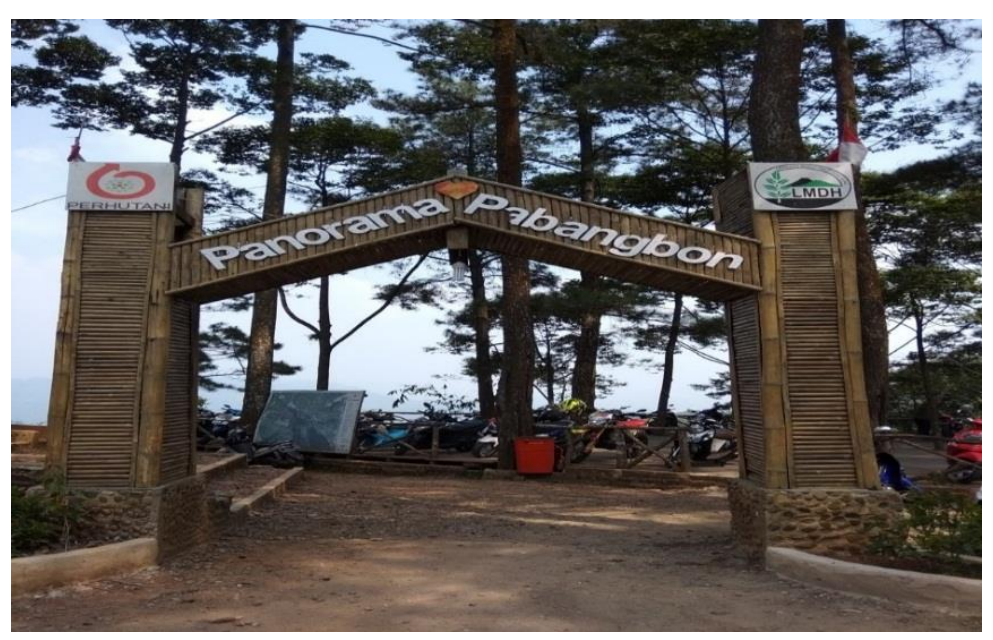

Gambar 1

Pintu Masuk Wisata Pabangbon 


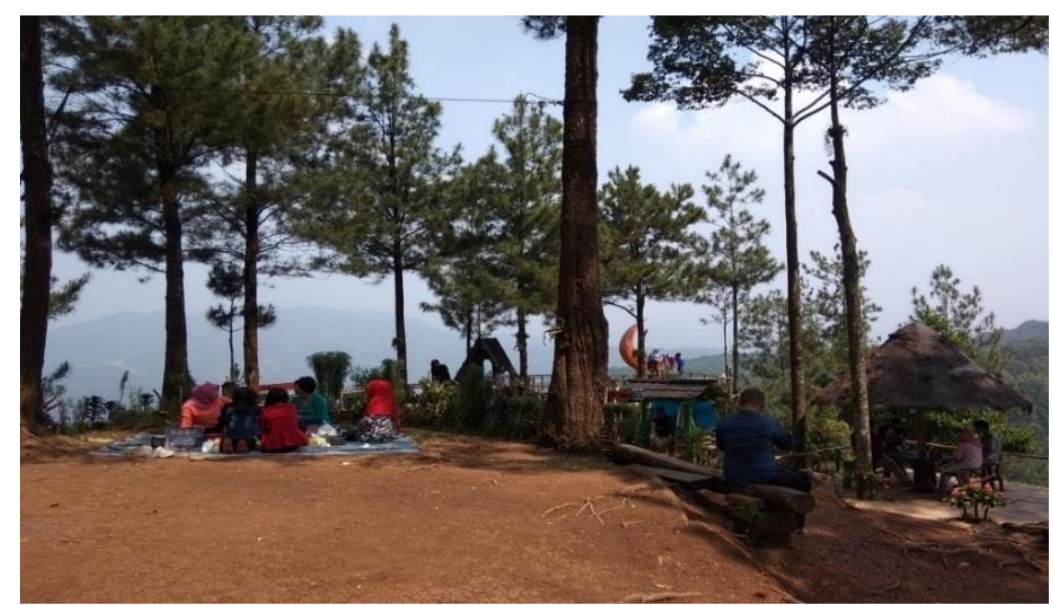

Gambar 2

Pemandangan Alam Wisata Pabangbon

Dari hasil analisis data yang diperoleh dari responden melalui kuesioner meliputi demografi, karakter, psikografi wisatawan. Sebagian besar wisatawan $(63,33 \%)$ yang datang ke Panorama Pabangbon adalah wisatawan berusia 20-22 tahun (remaja dan dewasa), namun belum menjadi pilihan utama wisatawan yang berkeluarga. Sebanyak 55\% wisatawan adalah wanita dan sebanyak $45 \%$ pria. Kebanyakan pengunjung masih lajang dan berpendidikan di perguruan tinggi dengan sebagian besar memiliki penghasilan bulanan sebesar 1-3 juta. Wisatawan yang berkunjung kebanyakan termotivasi untuk berekreasi. Kegiatan yang dilakukan wisatawan kebanyakan untuk mengambil gambar, menikmati suasana alami pohon pinus dan berkumpul bersama keluarga. Wisatawan mengetahui adanya tempat wisata ini dari paling banyak dari media sosial dan internet / browser. Mereka yang berkunjung biasanya pada hari libur menghabiskan waktu berwisata di Pabangbon rata-rata 1-3 jam dan mereka lebih suka datang pada pagi hari. Mengenai kualitas fasilitas yang ada di tempat wisata Panorama Pabangbon dimana menurut para pengunjung kondisi mushola kebersihan dan toilet umum sudah baik. Tentang keamanan berwisata di Panorama Pabangbon adalah sudah baik menurut sebagian pengunjung. Persepsi wisatawan tentang Panorama Pabangbon adalah sebagian wisatawan berpendapat pariwisata Pabangbon didirikan untuk menambah tujuan wisata di Bogor, sebagian lagi menjawab Pabangbon merupakan banyak spot berfoto yang bagus. Sebagian besar wisatawan pariwisata Pabangbon bisa lebih maju, aman, dan nyaman. Ada sebagian kecil wisatawan yang berpendapat perkembangan Pabangbon cukup baik saat ini dibandingkan 2 tahun yang lalu. Wisatawan berharap pengembangkan Pabangbon dapat meningkatkan ekonomi untuk masyarakat sekitar. Wisatawan berpendapat pelayanan di Pabangbon sangat ramah, selebihnya wisatawan merasa cukup puas dengan pelayanan mereka.

Penduduk yang berada di sekitar Panorama Pabangbon didominasi oleh orang muda yang berumur 20-22 tahun dengan jenis kelamin mayoritas perempuan yang telah menikah. Pendidikan masyarakat kebanyakan lulusan SMA / SMK dan lulusan universitas. Penduduk sekitar memiliki usaha, toko atau warung, dan ada juga yang bekerja sebagi karyawan, selebihnya adalah pelajar. Penghasilan bulanan penduduk antara 1-6 juta per bulan. Masyarakat berpendapat jalur menuju Pabangbon adalah baik atau tidak ada kendala. Warga berpendapat bahwa kebersihan di Pabangbon sudah baik. Menurut penduduk yang menjadi daya tarik 
utama Wisata Pabangbon adalah sebagai tempat berfoto yang bagus, sebagai tempat outbond yang menarik, dan karena panorama alam di Pabangbon masih sejuk dan indah. Menurut 63,3 \% warga setempat berdirinya Pabangbon membantu kehidupan sosial ekonomi mereka.

Pengelola Panorama Pabangbon banyak yang berusia 20-30 tahun dan kebanyakan mereka adalah pria yang sudah menikah dengan tingkat pendidikan pengelola yang terbanyak adalah sekolah menengah atas / sekolah menengah kejuruan. Pengelola berpendapat pengembangan Panorama Pabangbon sudah cukup baik dan keberadaannya mempunyai pengaruh sangat baik terhadap lingkungan sekitar, ada sebagian kecil yang menganggap kurang dikembangkan. Semua pengelola setuju bahwa adanya kerjasama dengan penduduk setempat sangat penting bagi pengembangan tempat wisata Panorama Pabangbon.

\section{Strategi Pengembangan Pariwisata Panorama Pabangbon}

Analisis SWOT untuk menetapkan arahan, konsep strategis atau pemecahan masalah dalam melakukan aktivitas atau kegiatan dengan mempertimbangkan Kekuatan (Strengths), Kelemahan (Weaknesses), Peluang (Opportunities) dan Ancaman (Threaths) yang ada dan mungkin akan ada pada lokasi penelitian (Rangkuti 2001).

Potensi fisik yang dimiliki oleh Panorama Pabangbon antara lain adalah keindahan alam yang masih alami dan ada area untuk berkemah atau rekreasi, area jogging, tempat berfoto yang bagus, sehingga Panorama Pabangbon merupakan pilihan yang tepat untuk dijadikan salah salah satu destinasi bagi group tour di Bogor. Apalagi fasilitas umum seperti mushola, penjual makanan, toilet, tempat parkir, tempat sampah di Panorama Pabangbon sudah cukup memadai. Namun tetap perlu diterapkan strategi pengembangan pariwisata Pabangbon agar tetap bertahan dan lebih maju lagi kedepannya.

Tabel dibawah ini menerangkan faktor pendukung dan penghambat atau daftar faktor internal (kekuatan - kelemahan) dan eksternal (peluang - ancaman) tempat wisata Panorama Pabangbon dalam pengembangan pariwisata Pabangbon dan terkait erat dengan strategi yang harus dilakukan dalam pengembangan Panorama Pariwisata Pabangbon di masa yang akan datang. 


\section{Tabel 3. Matriks SWOT}

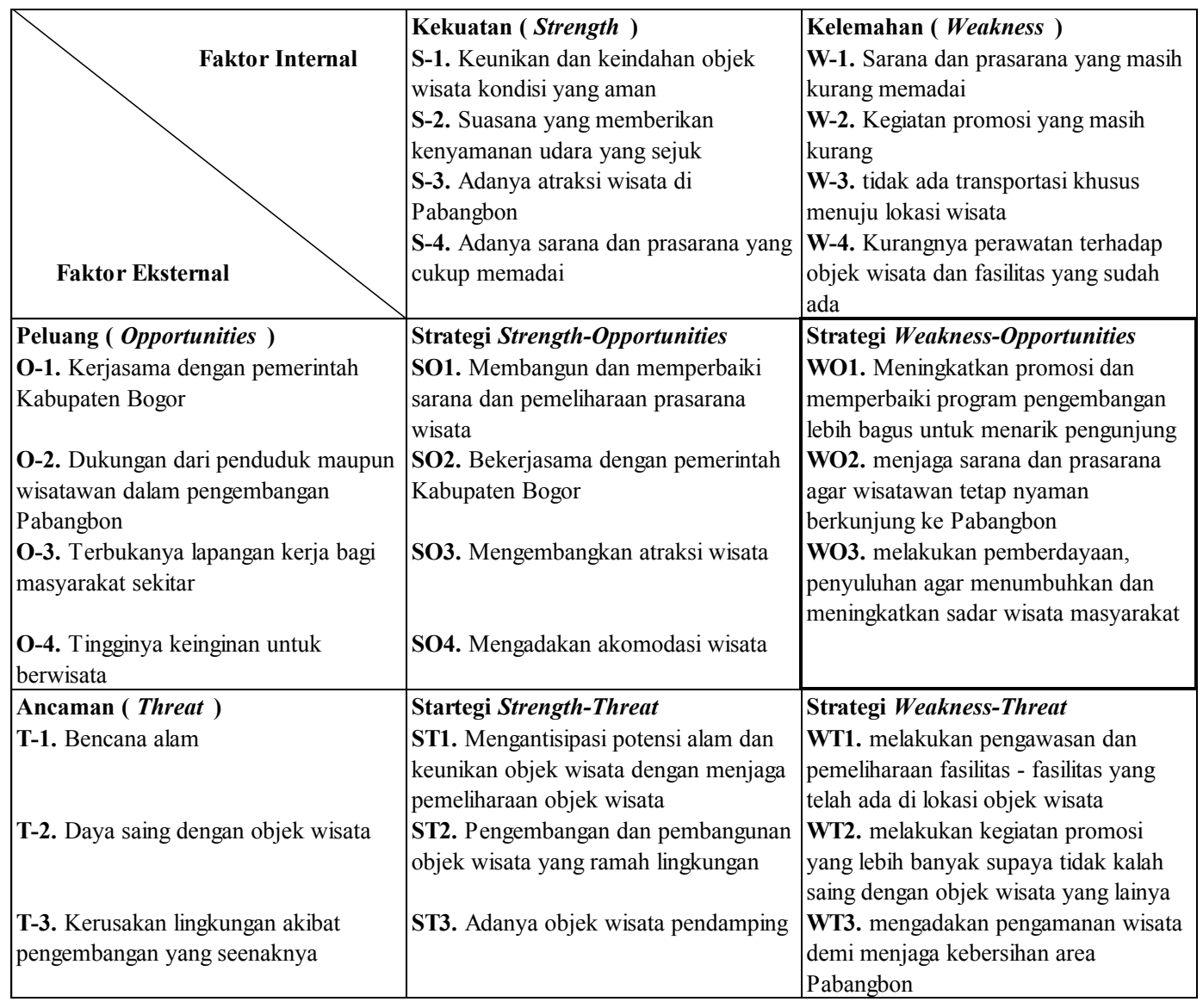

Berdasarkan hasil analisa SWOT, didapatkan strategi pengembangan pariwisata Panorama Pabangbon yang paling tepat dan dapat diterapkan oleh pengelola yang paling tepat adalah Strategi WO (weakness - opportunities) :

1. Meningkatkan promosi dan memperbaiki program pengembangan lebih bagus untuk menarik pengunjung

2. Menjaga sarana dan prasarana agar wisatawan tetap nyaman berkunjung ke Pabangbon

3. Melakukan pemberdayaan serta penyuluhan untuk menumbuhkan dan meningkatkan kesadaran masyarakat tentang pentingnya sadar wisata.

Alternatif pilihan strategi lainnya yang dapat diambil oleh pengelola tempat wisata Panorama Pabangbon adalah strategi agresif (strength - opportunities), strategi diversifikasi (strength - threat) ataupun strategi defensif (weakness - threat)

\section{SIMPULAN}

Berdasarkan hasil penelitian terhadap tempat wisata Panorama Pabangbon yang terletak di Desa Pabangbon, Kecamatan Leuwiliang, Kabupaten Bogor melalui analisis SWOT maka pengembangan Pabangbon Pariwisata, maka strategi alternatif yang utama yang harus dilakukan adalah mendukung strategi turnaround 
yaitu melakukan peningkatkan promosi dan memperbaiki program pengembangan lebih bagus untuk menarik pengunjung, menjaga sarana dan prasarana agar wisatawan tetap nyaman berkunjung ke Pabangbon dan perlu adanya pemberdayaan, penyuluhan agar menumbuhkan dan meningkatkan kesadaran masyarakat tentang pentingnya masyarakat sadar wisata sehingga objek wisata Panorama Pabangbon dapat menjadi salah satu tujuan wisata yang wajib dikunjungi di Bogor.

\section{DAFTAR PUSTAKA}

Abdul Wahab, Solichin. 2012. Analisis Kebijakan: Dari Formulasi ke Penyusunan Model-Model Implementasi Kebijakan Publik. Jakarta: PT. Bumi Aksara.

Batubara, Rima P. 2020. Strategi Pengembangan Oukup sebagai Ekowisata Kesehatan Kabupaten Karo. Jurnal Ilmiah Pariwisata. Vol. 25 No.2 pp. 121-132.

Deva, Yuwana. (2010). Analisis Permintaan Kunjungan Objek Wisata Kawasan Dataran Tinggi Dieng Kabupaten Banjarnegara.

Kotler, Philip \& Keller, Kevin Lane. 2009. "Manajemen Pemasaran”, Jakarta Penerbit: Indeks, 2009, hal. 63.

Marpaung, H. 2002. Pengetahuan Kepariwisataan. Ed Revisi. Alfabeta. Bandung. Rangkuti, F. (2001). Analisis SWOT Teknik Membedah Kasus Bisnis. Jakarta: PT. Gramedia Pustaka Utama.

Republik Indonesia. Undang - Undang no. 10 tahun 2009 tentang Kepariwisataan. Yoeti, O. A. (1997). Perencanaan dan Pengembangan Pariwisata. Penerbit: PT. Pradnya Paramita (cetakan pertama). Jakarta.

Romani, S. 2006. Penilaian Potensi Obyek dan Daya Tarik Wisata Panorama Pabangbon Serta Alternatif Perencanaannya di wisata Panorama Pabangbon. Skripsi. IPB. Bogor.

Sari, D. (2019). Motivation towards Inbound Tourism: A Study of Middle East Tourist. E-Journal Of Tourism, 235-251. 